INTERNATIONAL JOURNAL OF

MULTIDISCIPLINARY STUDIES IN ARCHITECTURE

AND CULTURAL HERITAGE

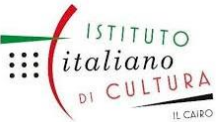

\title{
Using Museum Technology in the Temporary Exhibitions: A Case Study on the
} Temporary Exhibition of the National Museum of Egyptian Civilization

Sayed Abuelfadl Othman Ahmed a, *

a PhD Candidate Heritage and museum studies, Helwan University, Egypt

\begin{abstract}
Museum Technology is something very essential in our world today. Museum Technology is one of the main tools that use in museums to attractive the visitors through different kinds of technology. We can see museum technology in different exhibitions inside the museum permanent or temporary therefore this study will focus on the using of museum technology in the temporary exhibitions.

The study will apply the using of technology on one of the temporary exhibitions at the National Museum of Egyptian Civilization in Cairo. The paper will be including the different types of technology that is used in exhibitions and the benefits of these types for the visitors and for the museum itself.

Keywords

Storytelling Tools.

Digital Collections.

UNESCO.

NMEC.

Globalization
\end{abstract}

Introduction

Museums are looking for new ways to engage their visitors, and technologies like thosethat AR and VR add to their arsenal of educational and storytelling tools. Museums are naturalstorytellers eager to craft and distribute new stories in new ways. The best use of digital is to not make you aware of the technology, but to make you aware of the art.

Using museum technology now is one of the essential ways to engage visitors and let them interact with this technology. We can use it in the temporary or permanent exhibitions inside museums.

In this paper, we will focus on using the museum technology in the Temporary Exhibition of the National Museum of Egyptian Civilization in Egypt. In addition, it will be focus on the types of technology and benefits from it in this exhibition and the possibility of benefits from this technology in the permanent exhibitions in the 
INTERNATIONAL JOURNAL OF

MULTIDISCIPLINARY STUDIES IN ARCHITECTURE

AND CULTURAL HERITAGE

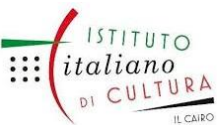

museum. Is it possible to benefits from it or not? In addition, what can museum do in this case?

By using new technology, museums can build knowledge bases around information about collections. A collection object can be the central link for information about past and present, places, people and concepts, technologies, ways of working and evidence of the naturalworld. 'Digital Collections' explains how this vision can be realized. Sound, video and animations can be digitized and developed as a central resource that can be drawn on for manyvaried access routes: via the World Wide Web; CD ROMs; through on-gallery screens, and other future products still in development. (Keene, S. 2012).

These technological capabilities raise many compelling issues that need to be understood in order to successfully develop information collections.

\section{The National Museum of Egyptian Civilization:}

The National Museum of Egyptian Civilization is considered to be one of the main projects sponsored by the United Nations represented by the UNESCO thus their special attention and "full" support since 1982. The project included the first \&only campaignorganization in the world to create a museum in Aswan and Nubia Civilization in Cairo. (Moniem, A. A., 2005).

There is close cooperation between Egypt and UNESCO in defining the objectives of the museum, consultancy and expertise in various fields relating to the establishment of the museum. Also, there's an ongoing dialogue between the Egyptian team and the UNESCO thatis will be active until the official opening of the museum to the public. (Moniem, A. A., 2005). 
INTERNATIONAL JOURNAL OF

MULTIDISCIPLINARY STUDIES IN ARCHITECTURE

AND CULTURAL HERITAGE

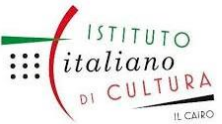

ISSN: $2735-4415$

VOLUME 3, ISSUE 2, 2020, $106-117$.

www.egyptfuture.org/ojs/

\subsection{NMEC's Mission:}

NMEC's mission is to present to its visitors Egyptian Civilization - one of the main roots of world civilization - as a layered cumulative product of the interaction of the Egyptianpeople on their land through history.

\subsection{Objectives:}

- NMEC portrays the Egyptian contribution to world civilization in a way that extendsbeyond what is visible, to include information about: knowledge, skills and values.

- $\quad$ NMEC reflects the richness and diversity of Egyptian culture.

- NMEC utilizes state of the art exhibition methods to present innovative and interactive visions of Egyptian civilization, thus connecting the past with the present.

- In an age of globalization, NMEC is an educational "lighthouse" projecting the different facets to Egyptians: crafts, history, languages, etc., to strengthen contemporary, especiallychildren, Egyptians by enabling them to self-discover their identity.

- NMEC is a pioneering institution of this kind in the region; it can thus become a world- wide hub for inter-cultural dialogue.

- $\quad$ NMEC is a National center for research, conservation, restoration and a secure antiquity storage facility.

- NMEC provides the highest security area for one of the world's oldest civilizations including the collection of Egyptian Royal mummies. 
INTERNATIONAL JOURNAL OF

MULTIDISCIPLINARY STUDIES IN ARCHITECTURE

AND CULTURAL HERITAGE

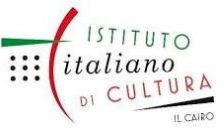

- NMEC is a sustainable Museum by introducing and creating new activities to ensure partial income generation of its necessary long-term running costs. (Moniem, A. A., 2005).

\section{The Temporary Exhibition Gallery:}

The temporary exhibition hall was opened at the National Museum of EgyptianCivilization on $15^{\text {th }}$ February. As a partial opening of the museum, this includes a temporary exhibition on "Egyptian crafts and industries across Ages", which includes about 420 artifactsthat reflect the development of Egyptian crafts throughout the Historical Ages and so far, whichhas an area of 1000 square meters.

This exhibition presents an amazing collection of "Egyptian handcrafts through the ages", which provides us with insights on Egyptian culture, its depth and continuity. The exhibition covers four topics that represent the multifaceted technologies the Egyptians employed: pottery manufacture; textile production and weaving; jewellery making; and carpentry. Through these crafts, Egyptians exploited their environment to the maximum, developed intricate technologies, and imported and adapted new techniques and knowledge over thousands of years (N. M., 2016). It will also include a number of figures and graphic illustrating the shape of the makers of these crafts, their clothes and their bodies as well as the materials used in their craft and the preparation of large electronic screens, a collection of documentary films on each craft and its evolution through the ages. Here we will introduce a brief about each manufacture as following:

\subsection{Pottery:}

Egypt possesses one of the longest uninterrupted traditions of pottery production in theworld. While pots were often functional, different methods were used to add decoration, colour,lustre and glazes to them. Clays were also used to 


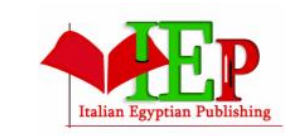

ISSN: $2735-4415$
INTERNATIONAL JOURNAL OF

MULTIDISCIPLINARY STUDIES IN ARCHITECTURE

AND CULTURAL HERITAGE $\vdots:: \begin{gathered}\text { istituto } \\ \text { italiano } \\ \text { ol CULTURA }\end{gathered}$

www.egyptfuture.org/ojs/

make figurines, lamps, toys and even pipes for smoking. The various techniques and different clays used in the making of these artefacts, as well as their decorations provide archaeologists and ceramicists with invaluable informationon their dates and provenance. Ceramics were not only functional, but their decoration often carried social and religious connotations, in addition to purely aesthetic embellishments. Experience grew through interaction with neighbors and conquerors, as they added new technologies to their repertoire during the GrecoRoman, Coptic and Islamic Periods. Many ofthe functional ceramic vessels are still being produced and used widely in modern Egypt. (N. M., 2016).

\subsection{Weaving:}

Weaving is another craft that made use of the rich Egyptian environment. Locally sourced flax was used to make linen from very early on in Egyptian history, and animal wool was also used for warmer textiles. In post-pharaonic Egypt, weaving reached new levels, withthe introduction of cotton, wool and silk to the original linen of ancient Egypt. Added to this are the Persian and Greco-Roman motifs that appear alongside Byzantine Christian symbols togive Coptic textiles their own specificity. These newly introduced decorations, woven or sometimes embroidered were so valued that they were often cut out of older warn clothes in order to be fixed on newer ones. With the Arab conquest of Egypt further refinement was added, such as the Tiraz silky fabrics reserved for royalty and the elite. Many of the weaving traditions in Egypt are still preserved, particularly in the region of Akhmim in Upper Egypt, where hand woven fabrics on traditional looms are still manufactured. (N. M., 2016).

\subsection{Carpentry:}


INTERNATIONAL JOURNAL OF

MULTIDISCIPLINARY STUDIES IN ARCHITECTURE

AND CULTURAL HERITAGE

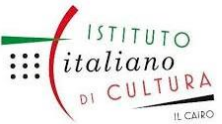

Despite Egypt's arid environment and scarcity of trees, Egyptian woodworkers also produced masterpieces. Different qualities of wood had to be imported from the Levant or fromAfrica to use in specific building and for the manufacture of boats, statuary, and furniture of different kinds; while local wood was more frequently used in the making of tools, small statuary and models of daily life scenes, such as the models found in some tombs of wealthy ancient Egyptians. A mastery of woodcarving, particularly manifested in statuary and small objects such as cosmetic tools, for example, is also well represented later in the wood carvingof the doors and ceilings and other architectural elements of the Coptic and Islamic monumentsin Egypt. Traditional and intricate decoration of wood might be a dying trade, but specialised woodworkers strive to keep their traditions going. (N. M., 2016).

\subsection{Jewellery:}

As for jewellery, which is the last of the crafts presented in this exhibition, it has beenpart of Egyptian culture since we have material evidence of human activity. Present in its earliest graves, jewellery has been made from a vast diversity of materials often carrying a particular symbolism and used for a vast array of different purposes. Apart from being an adornment for men as well as for women, the prophylactic role of jewellery and its stones in religion and magic is also well known. (N. M., 2016).

\section{The Museum Technology in the Temporary Exhibition:}

There are different types of technology that were used in this temporary exhibition as

follow; 


\subsection{The Wall of Knowledge (Scenes from Rekhmire Tomb at Thebes):}

The tomb of Rekhmire at Thebes, Rekhmire occupied the Viziership under

Thutmoselll and remained there in turn until the first part of the reign of Amenhotep. His tomb TT100is carved at the base of the hill of Sheikh Abd elQurna. It is exceptional, and historicallyimportant for its pictorial quality. The presentation of the workmen in the chapel of Rekhmireis exceptional and is a major source of information about crafts in Ancient Egypt. It showsmainly the crafts of leatherwork, carpentry as well as metal work and goldsmith. (N. M., 2016).

The idea from this wall or other walls is to download an application on our mobile andafter that use this application and put it on the scenes of the wall to see the original colors of these scenes and also you will find information about each scene. This kind of technology give the visitors to interaction with these walls give them the chance to see tombs with its scenes inside a museum not in its original places.

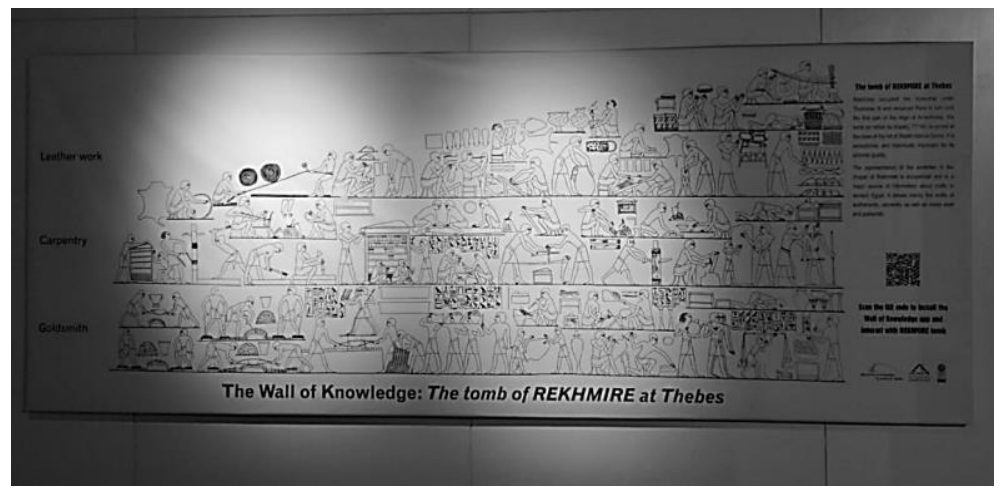

Fig. 1 - the Wall of Knowledge; the Tomb of Rekhmire at Thebes, Taken by Sayed Abuelfadl.

\subsection{The Reconstruction of the Chair of Queen Hetep-Heres (Movie):}

In this video on a small tablet a reconstruction of the chair of queen HetepHeres, mother of King Khufu the owner of the great pyramid. This chair came from 
her tomb at the pyramids area. This video introduces to the visitors the idea of making this chair, how it made,how many pieces used in it, the way of making and symbols that was used like Lotus flowers and Hieroglyphic writings in different places on the chair. This way of display gives the visitors' time to stand in front of this video until the end but without this video the visitor will pass quickly in front of it. Sometimes, visitors need to understand the stories of making these artifacts. (N. M., 2016).

2016).

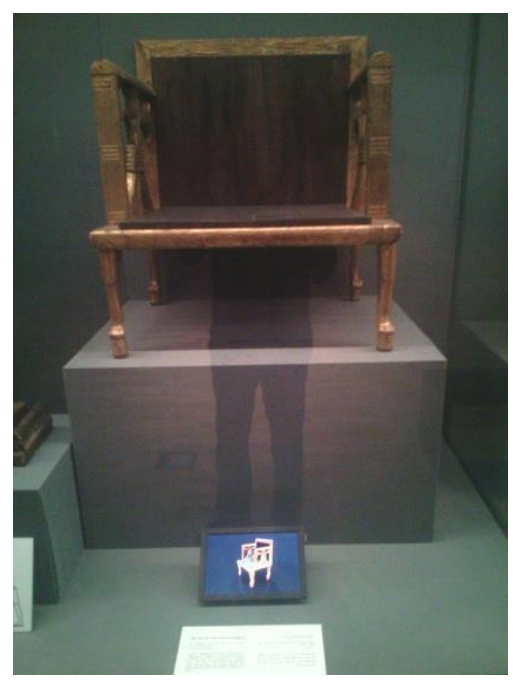

Fig. 2 - Movie of the Reconstruction of the Chair of Queen Hetep-Heres, Taken by Sayed Abuelfadl.

\subsection{The Reconstruction of the Egyptian Chariot (Movie):}

In this video on a small tablet also show us a reconstruction of the Egyptian chariot, how it was made and how many pieces was used in it. In ancient Egyptian society chariotry stood as an independent unit in the King's military force. Chariots were first introduced as a weapon in Egypt by the Hyksos in the 16th century BC. The Egyptians developed their owndesign of the chariot. (N. M., 2016). 
INTERNATIONAL JOURNAL OF

MULTIDISCIPLINARY STUDIES IN ARCHITECTURE

AND CULTURAL HERITAGE

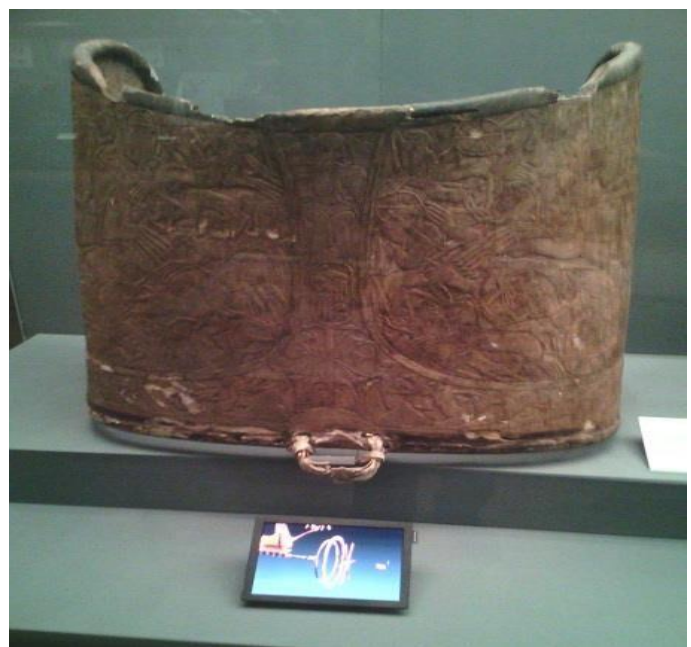

Fig. 3 - Movie of Reconstruction of the Egyptian Chariot, Taken by Sayed Abuelfadl.

\subsection{Touch Screens:}

Empower your visitors to learn, explore and discover. The old cliché "Look but don't touch" no longer applies. Instead you are now able to give visitors a much more hands-on experience through the use of touch screen interactivity. Touch screen solutions attractattention and empower your visitors to learn about, and engage with your exhibits for a truly immersive and memorable learning experience. (N. M., 2016).

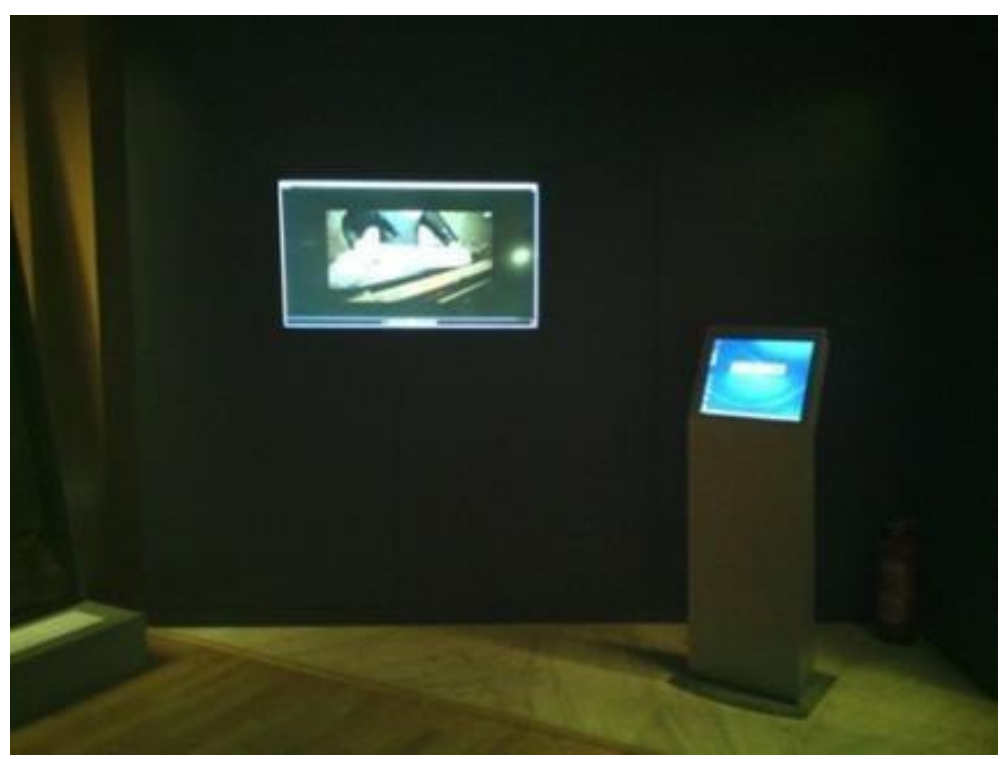


INTERNATIONAL JOURNAL OF

MULTIDISCIPLINARY STUDIES IN ARCHITECTURE

AND CULTURAL HERITAGE

Fig. 4 - Example of Touch Screens, Taken by Sayed

Abuelfadl.

\subsubsection{Benefits of Touch Screens for Exhibit Information:}

- Bring an exhibit to life with a mixture of narration, sounds, videos, pictures, maps, 3D andmore.

- Empower visitors to engage at a deeper level by providing additional information about anexhibit or adding some further context to it.

- Enable visitors to learn using their preferred learning styles (Visualizing, Auditory andKinesthetic).

- Inspire visitors to discover more and to retain the knowledge more effectively throughinteractivity.

- Encourage socially interactive visitor experiences.

- Easily provide multilingual information.

- Save on guide costs by allowing visitors to help themselves to additional information.

- Increase the accessibility and relevance of information by providing it in different formatssuitable for various demographics such as young children, adults, students and experts.

In the National Museum there are two touch screens with two separated screens for display what you are deal with and the majority of the visitors when they visit the exhibition and see these touch screens, they stop in front of them and need to deal with and interactive because they didn't see something like that in the Egyptian museums. The contents of these touch screens are some videos about handicrafts in Egypt through the ages and you can see anddeal with to see what you want.

\section{Four Large Screens:}


INTERNATIONAL JOURNAL OF

MULTIDISCIPLINARY STUDIES IN ARCHITECTURE

AND CULTURAL HERITAGE

One of the main technology used in the temporary exhibtion are 4 large screens show us four movies one for each handicraft at the top of one of the gallery sides. This kind of moviesis a mix between the old and the new during the meeting with a group of skilled manufacturersin the field of their industries. These kinds of movies give the visitors a brief information abouteach manufacturer and give them the time to think in the continuty of the handicarft trough theages.

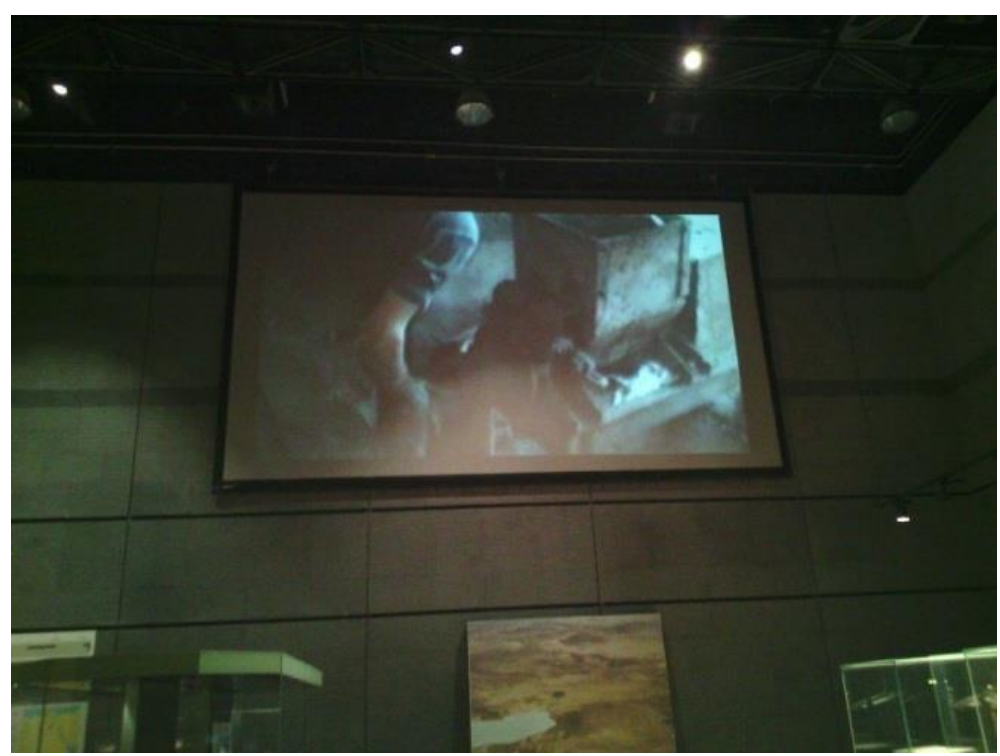

Fig. 5 - Example of Large Screen, Taken by Sayed Abuelfadl.

\section{CONCULSION:}

Museums are always looking for ways to make their exhibitions more exciting. Now, new technologies are making that easier. From these ways, the using of museum technology as a tool of interaction between the visitors and this technology inside museums. Now this technology is one of the main tools of any museum all over the world. 
INTERNATIONAL JOURNAL OF

MULTIDISCIPLINARY STUDIES IN ARCHITECTURE

AND CULTURAL HERITAGE

Finally, we can say that the museum without technology is something unacceptable because from my point of view, technology gives museums live again.

\section{Biography:}

Sayed Abuelfadl Ph. D Candidate Heritage and museum studies, Helwan University, Egypt, graduated from Faculty of Archaeology Cairo University, Holding an MA in Museum Studies from Faculty of Tourism and Hotels Management, Helwan University in 2017 and works as Curator at the National Museum of Egyptian Civilization (NMEC) Egyptian Ministryof Tourism and Antiquities Since 2004.

\section{References:}

- $\quad$ Keene, S. (2012). Digital collections. Routledge.

- $\quad$ Marty, P. F., \& Jones, K. B. (2008). Museum informatics: People, information, and technology in museums(Vol. 2). Taylor \& Francis.

- Moniem, A. A. (2005). The National Museum of Egyptian Civilization. Museum International, 57 (1-2), 24-30.

- $\quad$ N. M. (2016). Egyptian Crafts through the ages [Catalogue]. Cairo: Ministry of Antiquities.

- The National Museum of Egyptian Civilization. (2011). The National Museum of Egyptian Civilization[Press release]. Cairo: Ministry of Antiquities: Author.

- $\quad$ https://intouchscreens.com.au/industries/touch-screens-for-museums/

- $\quad$ http://nmec.gov.eg/

- $\quad$ http://www.unesco.org/new/en/culture/themes/museums/museum-projects/thenational-museum-of- egyptian-civilization/

Received: February 15, 2018

Accepted: April 20, 2018 